\title{
Performance Analysis of a Steam Power Plant: A Case Study
}

\author{
Wadhah H. Al-Taha ${ }^{1,2, ~ *}$, Hassan A. Osman ${ }^{2}$ \\ ${ }^{1}$ North Technical University, Iraq \\ ${ }^{2}$ Sudan University of Science \& Technology, Sudan.
}

\begin{abstract}
In this work, the evaluated performance of thermal station is mechanically studied by determining the performance parameters for generative unit, which it is given the calculation model by doing heat balance for each one of its principal parts. A comparison is done between the particle results, which are obtained from the station and the theoretical results which its calculated from the basic first law thermodynamics, The different working loads $(40 \%, 70 \%, 100 \%)$ of its completes load have been considered in order to determine the optimum working circumstances, in addition to demonstrate the effect of some working and environmental circumstances on unit performance.
\end{abstract}

\section{Introduction}

An accurate prediction of the performance of a power plant, with the corresponding detailed evaluation of its thermodynamics variables, allows to avoid undesirable or abnormal operating conditions or to anticipate solutions to certain unusual operating conditions like those derived from maintenance labours [1-4]. Currently, the electric is the most important form of energy used in the world [5-7]. For this reason, power plants necessary to study as the crucial energy systems $[8,9]$. The thermal power plants have greater power production among different types of power plants [10-13].

The steam power plant working is based on Rankine cycle, where the increasing of the superheated steam temperature lead to improving the thermal efficiency of cycle as thermodynamics process [14-16]. Later, researchers tried to improve the efficiency of the plant by increasing steam pressure, which resulted in degradation of the steam quality at the turbine exhaust [17]. To overcome such problems, steam reheating was introduced after high pressure turbine exhaust, which leads to decrease of the moisture content at low-pressure turbine exhaust. The effect of reheat pressure on cycle efficiency was investigated [18-20].

These stations were limited at the beginning of the work in which the simple Rankin Cycle, which did not exceed the thermal efficiency (10\%), as a result of technological progress and the continuing search continued in the introduction of improving the engineering material improvements and add other parts to develop a thermal cycle might get on the highest thermal efficiency, use common reheat-regenerative compound cycle, were obtained by the thermal efficiency of up to about $44 \%$ [21], As a result of the sharp decrease

* Corresponding author: waddhahhussein@ yahoo.com 
in production of electric power in most of the stations, in order to determine the location of any station from the rest of the stations in terms of generated electric power has been selected Baiji thermal power plant in Iraq to assess its performance and by comparing the theoretical results with readings process, as well as examine some of the factors influencing on this performance in order to provide some suggestions to improve performance and thereby increase the generated capacity. The station Baiji thermal power consists of six generating units are similar, with a maximum generating capacity of each of them (220MW), which operates on the basis of the reheat-regenerative compound cycle, and works with various fuels. The study of plant performance, for thermal analysis based on the first law of thermodynamics on the third generating unit to which its took as a model for the analysis, when loads obstetric different cover $(40 \%, 70 \%, 100 \%)$ of the full load, has been appointed different points in the session and to identify water and steam where the conditions for the purpose of analysis and calculation of the specific heat content of water vapor and the values, Fig.(1) shows the thermal cycle of the unit generating scheme at $100 \%$ load. This study is based on $220 \mathrm{MW}$ steam power plant unit and it of five major components boiler, steam turbines as a high pressure turbine, intermediate pressure turbine and low pressure turbine, condenser, feed water pump - pump after condenser and pump after deaerator and feed water heater - one open feed water heater for high pressure turbine, with the intermediate pressure turbine there are three feed water heater and at low pressure turbine they located three feed water heater.

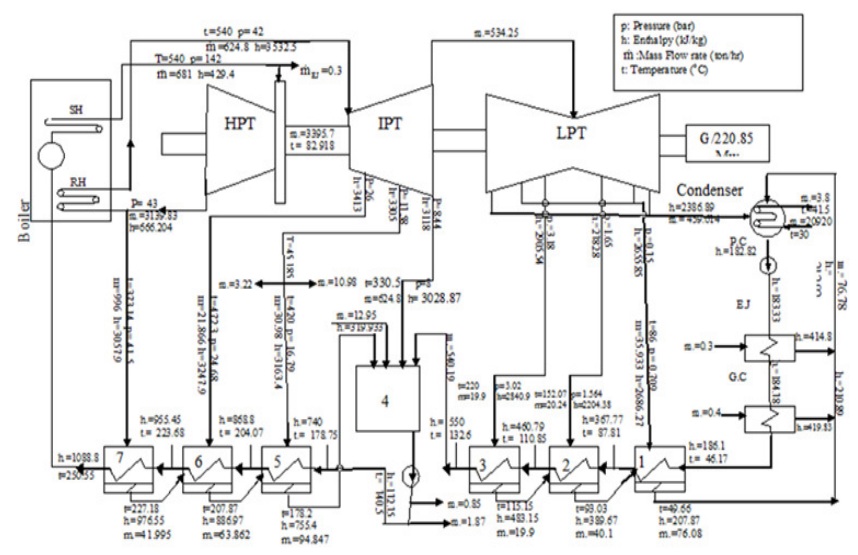

Fig. 1. Thermal cycle of the unit generating scheme at $100 \%$ full load.

\section{Plant performance parameters}

Expressed as the thermal plant performance through the use of the following:

\subsection{Thermal Efficiency}

It represents the amount of thermal energy entering the system, which turn to work, also known as (Cycle Efficiency), It represents the ratio between net work outside of the turbine to the thermal energy transmitted to the steam in the boiler. And can be expressed in the following equation [6].

$$
\eta_{t h}=\frac{W_{n e t}}{Q_{i n}}
$$




\subsection{Heat Rate}

When conducting analyses of pregnancy variable is the expression of the thermal plant performance using more useful to express the thermal efficiency of heat rate, and the rate of heat is the ratio between the amount of thermal energy received by the steam in the boiler and net filled the turbine, it is the inverse of the thermal efficiency, so it can represent the following relationship [3].

$$
\mathrm{HR}=\frac{3600}{\eta_{\mathrm{th}}}
$$

\subsection{Overall Efficiency}

Expresses the overall efficiency of the overall plant efficiency, they are one of the important parameters in the station, which it calculates all the losses in the thermal cycle, and is expressed in the following equation [22].

$$
\eta_{\mathrm{o}}=\eta_{\mathrm{th}} * \eta_{\mathrm{b}} * \eta_{\mathrm{m} . \mathrm{g}}
$$

Where:

$\eta_{\mathrm{b}}$ : Representing the efficiency of the boiler.

$\eta_{\mathrm{m} . \mathrm{g}}$ : Representing the multiplication of the mechanical efficiency of the turbine with an efficiency of the electric generator.

Overall Efficiency is the ratio between the net energy produced in the electric generator and thermal energy entering the generating unit as a result of fuel combustion, and can be calculated from the following equation [23].

$$
\eta_{o}=\frac{3600 * p}{\dot{m}^{*} L H V_{f}+\sum \text { HeatCredits }}
$$

\section{Results and discussion}

After the heat and mass balance of the generating unit parts of the power plant have been getting the results shown in the figures from 2 to 12 for the loads $(40 \%, 70 \%$, and $100 \%)$ of full load, and in comes presentation of these results and discussed:

\subsection{Factors affecting the performance of the generating unit}

From change thermal efficiency, overall efficiency and net rate heat with the unit generating change, which is represented by fig. 2, notes that the net heat rate of less than the increase in load unit, has reached its highest value $(8334.7 \mathrm{kj} / \mathrm{kw} . \mathrm{hr})$ at $(40 \%)$ of full load and decreases with the increasing load of up to $(8151.4 \mathrm{kj} / \mathrm{kw} . \mathrm{hr})$ at full load $(100 \%)$, also notes that the thermal efficiency was $(43.19 \%)$ at $40 \%$ of full load gradually increases with pregnancy for up to a higher value $(44.16 \%)$ at full load, as well as the case for overall efficiency, it also increases with the pregnancy, where happen to earn a rate of $(1.29 \%)$ when the overload of 
(40\%-100\%), a result of the gain made in the thermal efficiency, they are applied to the Eq. (3). As compared to the theoretical results to change the thermal efficiency with pregnancy with practical values her for Change (2001), as shown in fig. 3 as large and clear between the two different shows is the result of several reasons, including old station and extinction happening as a result of destruction, smashing done to them as well the destruction of some parts of the boiler due to the high combustion temperature is uncontrolled.

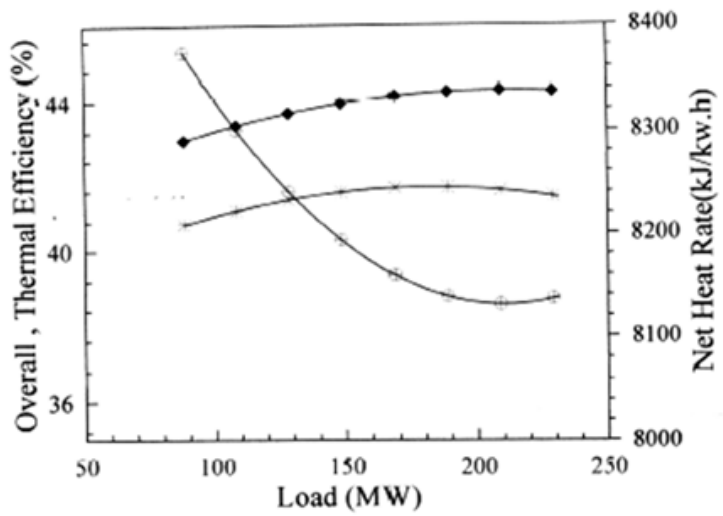

Fig. 2. The change of efficiencies with unit load.

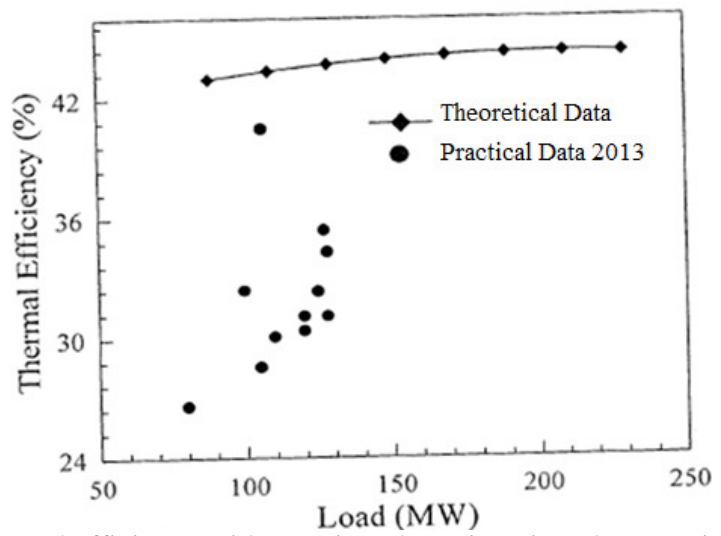

Fig. 3. The change in thermal efficiency with carrying obstetric unit and comparing the theoretical results with the practical of 2013.

In the condenser, which is one of the main parts that directly affect the performance of the generating unit, the relationship between the amount of thermal energy rejected in condenser with pregnancy generative change painted, as shown in fig. 4 , where the increase in the amount of thermal energy rejected from the notes $(400 \mathrm{MJ} / \mathrm{hr}-1000 \mathrm{MJ} / \mathrm{hr})$ when the increase in load (40\%-100\%) of the carrying unit generative, and attributed to it at high loads higher amount of heat added to the represented turbine to increase the flow of steam rate in the session and down to increase the flow of steam rate home to the condenser, which leads to offering the largest amount of this heat in the condenser when the increased load, it is done to increase the amount of cooling water inside the condenser, which change temperature is the other depending on the changing seasons of the year, where this change into account taking in a statement its impact on the condenser performance, it has been study the effect of changing temperature entering the cooling water to the condenser performance, as reflected in fig. 5, which is intense pressure change with thermal load at different temperatures to enter the cooling water, it is noted this figure shows that the intense pressure changes from 
(0.026bar-0.086bar) when convective change of condenser $(100 \mathrm{MJ} / \mathrm{hr}-100 \mathrm{MJ} / \mathrm{hr})$ when the inlet temperature on the cooling water $\left(18^{\circ} \mathrm{C}\right)$, while intense pressure changes from (0.056bar-0.12bar) when changing the load of $(100 \mathrm{MJ} / \mathrm{hr}-1800 \mathrm{MJ} / \mathrm{hr})$ when inlet temperature for cooling water $\left(38^{\circ} \mathrm{C}\right)$, it is so, we conclude that the efficiency of the unit generating in the winter to be higher compared with the efficiency in the summer.

In this research was the study of the performance of heaters seven of their number, with the main objective lies of this study is to determine the role of each heater in raising nutrition water temperature and improving the thermal efficiency of the cycle as well as the possibility of dispensing with any one of these heaters by lifting or holiday effect the efficiency and performance of the unit, when note form fig. 6 which represents the change in thermal efficiency with a number feed water heaters for feeding explains the contribution of each heater and its role in improving the thermal efficiency of the unit when the full load generative, it has been shown that when you cancel all the heaters and the functioning of the unit cycle reheating and pressuring design $(142 \mathrm{bar})$ and $\left(540{ }^{\circ} \mathrm{C}\right)$ outside of the steam from the boiler was the thermal efficiency of the $(38.87 \%)$, but when you add the first heater, the efficiency increases to up to $(39.98 \%)$, where he continues to increase as the number of heaters to increase to up to $(44.16 \%)$ when you add the heater seventh, which contributes to the highest extent in raising the efficiency with high thermal efficiency when added to $(42.14 \%-44.19 \%)$, and so we find that when lifting one heaters or holiday efficient session shall be equal to the efficiency in the first case before submitting it less improvement which contributes to its so heated in raising efficiency.

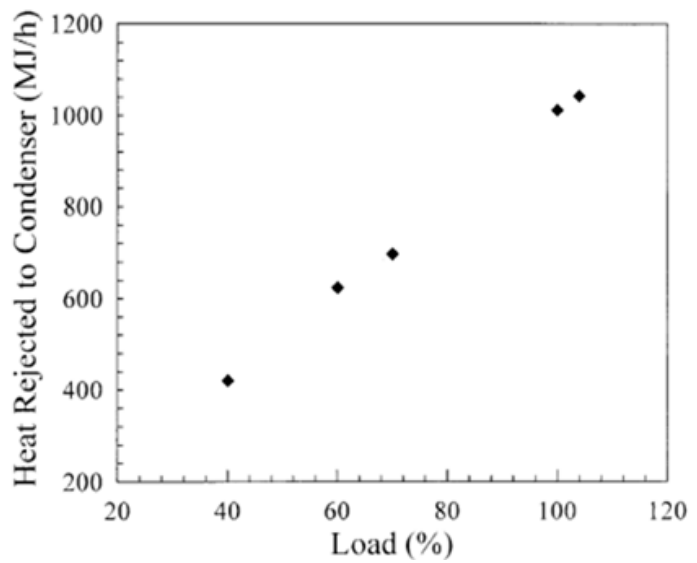

Fig. 4. The change heat rejected in condenser with unit load.

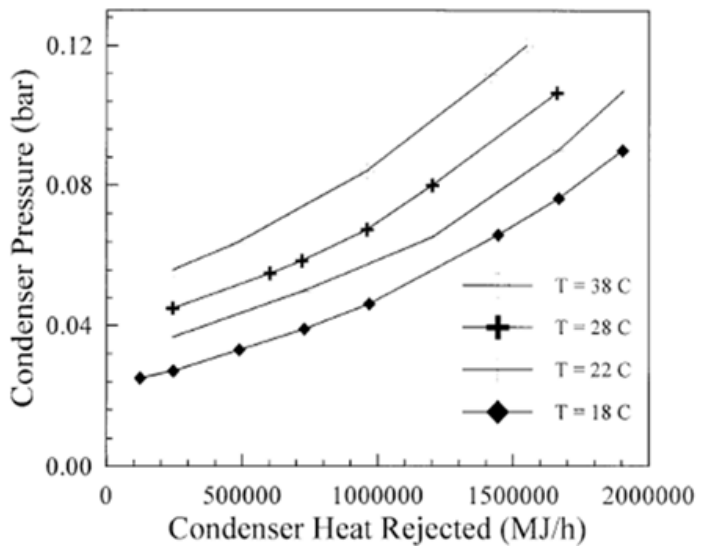


Fig. 5. The change condenser pressure with condenser heat rejected at various inlet cooling water temperature. 


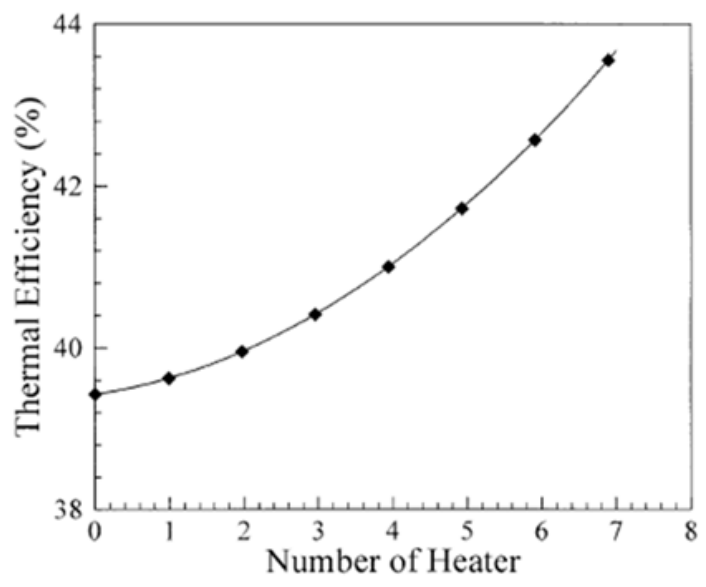

Fig. 6. The change of thermal efficiency with number of feed water heaters.

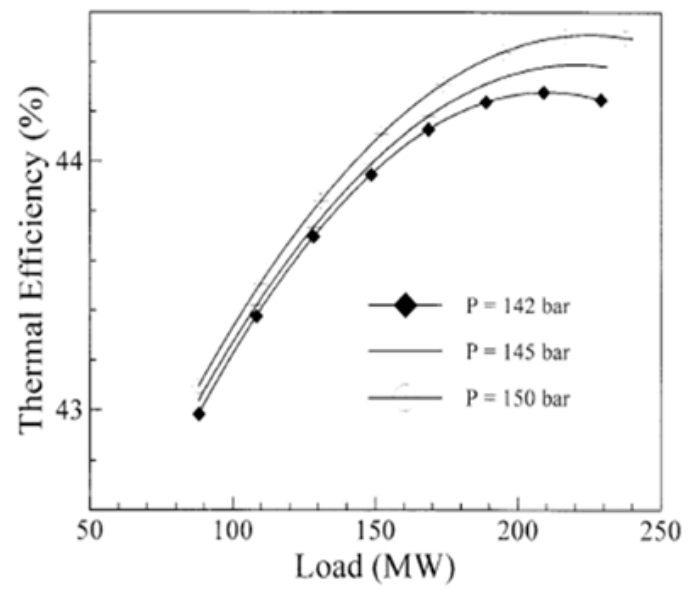

Fig. 7. The effect of initial pressure steam inside turbine on thermal efficiency.

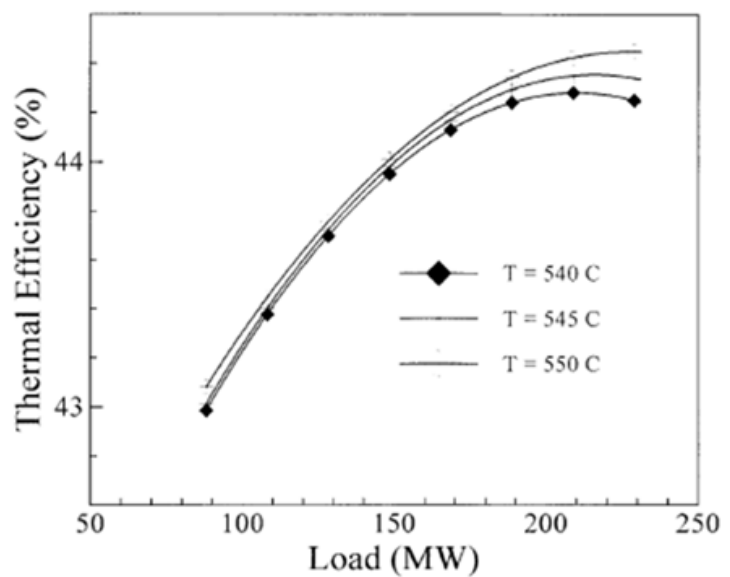

Fig. 8. The effect of initial steam temperature inside turbine on thermal efficiency. 


\subsection{Effect of changing factors of steam turbine}

This part includes a discussion of the results of the effect of changing pressure and temperature of the steam inside the turbine as well as the effect of the pressure change and temperature of the steam in the regenerative phase and their impact on the performance of the unit generating. It has been observed that the steam inside the circumstances changed to the turbine has an impact on performance parameters and of the thermal efficiency and the heat rate, which can be seen through the influence of the primary pressure steam difference which seems obvious when observing the fig. 7 , the increase in thermal efficiency by recorded $(0.32 \%)$ as a result of increased primary pressure (142bar-150bar) and at initial temperature of steam stay when $\left(540^{\circ} \mathrm{C}\right)$ and condenser pressure are constant, but when raising the initial temperature of steam inside the turbine by $\left(10^{\circ} \mathrm{C}\right)$, increase in temperature $\left(540^{\circ} \mathrm{C}-550^{\circ} \mathrm{C}\right)$ and when initial pressure remains at $(142 \mathrm{bar})$ and condenser pressure are constant, has been found that the thermal efficiency increase by $(0.72 \%)$ at full load as shown in fig. 8 which represents the change in thermal efficiency with the change of load unit when a different initial temperature of the steam inside the turbine.

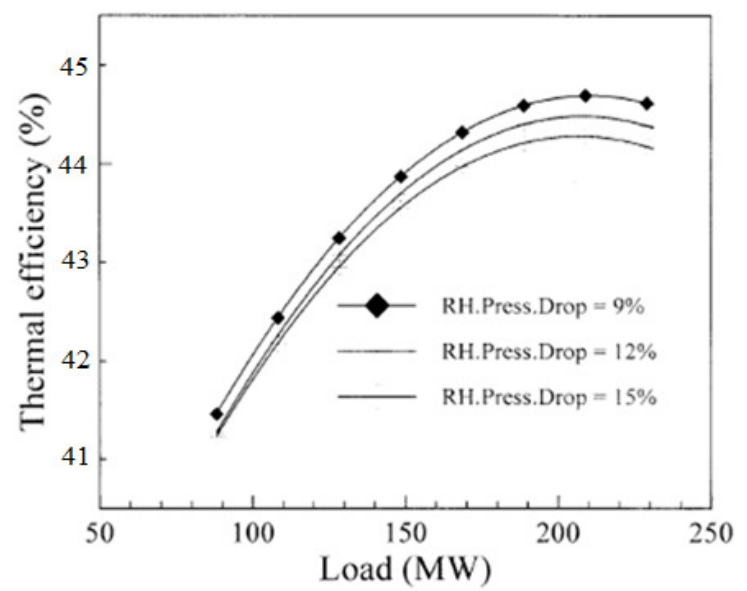

Fig. 9. The effect of regenerator pressure various on thermal efficiency.

Also, the steam properties in the reheated their importance in improving unity obstetric performance as the steam outside heat from a high pressure turbine process to reach its temperature to the original class primary when he entered into a turbine medium pressure, which is often used to increase the dryness fraction outside of the steam from the stage low pressure turbine the in order to keep the blades turbine corrosion and erosion that may affect them as a result of the steam moisture, as well as improve the performance of the unit, and on this basis he studied the effect of the pressure difference and the temperature of the regenerator on the performance of the unit, it is note form fig. 9, which represents a change thermal efficiency with a load unit when the steam pressure difference in regenerator, it was found that when the low pressure steam regenerator $(15 \%)$ and the temperature at $\left(540^{\circ} \mathrm{C}\right)$ with the initial steam conditions and the condenser pressure are constant, gets a reduction in thermal efficiency from their first by $(0.88 \%)$. But when increasing temperature steam regenerator by $\left(10^{\circ} \mathrm{C}\right)$ so, increase temperature of $(540 \mathrm{oC}-550 \mathrm{oC})$ lead to an increase in thermal efficiency by $(0.6 \%)$ at a steam pressure stay in the regenerator and initial steam conditions and condenser pressure are fixed condition as this can be seen in fig. 10 . 


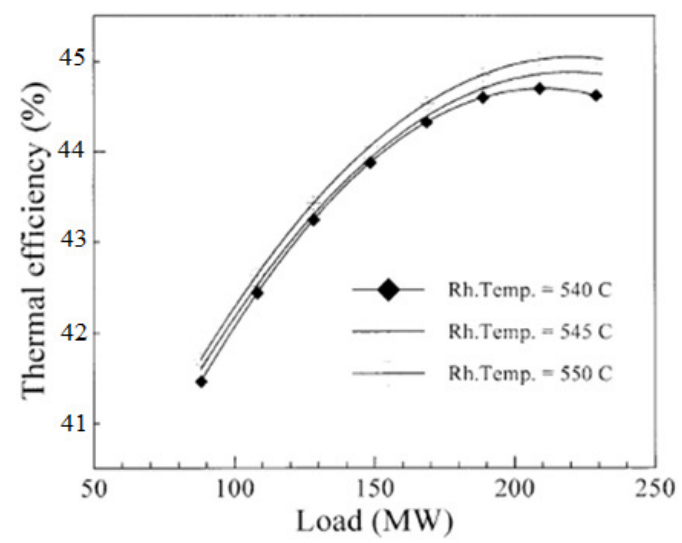

Fig. 10. The effect of regenerator temperature on thermal efficiency.

\section{Conclusion}

The main conclusions derived from the current study, the following points:

- From the analysis heat and mass balances of the unit generation power station and at different operational loads of loads $(40 \%, 70 \%, 100 \%)$ of the full load, taking into account the effect of the flow of steam rate Leech phases of the three turbine stages to the heaters nutrition water found it decreases with lower carrying the unit, they are linked by a positive relation with the load, as well as the temperature monitoring of steam Leech and water temperature and nutrition which are also reduced with low load generative.

- Top thermal and total efficiencies unit generating at full load (100\%) and decrease at partial load (40\%) and the lowest rate of heat net unit obstetric gets the full load $(100 \%)$ and increases when the partial load (70\%) and continues increase when the partial load $(40 \%)$, so it can be recommended for operation at full load, which is operating with its economically and very fit, while not recommended for operation at partial load (40\%) for the lower thermal and total efficiencies and high net heat rate.

The authors would like to thank Sudan University of Science \& Technology for providing laboratory facilities and financial.

\section{References}

1. Ibrahim, T.K. and M. Rahman, Int. J. Auto. Mech. Eng., 9: p. 1747 (2014).

2. Basrawi, F., et al., Energy, 97: p. 262-272 (2016).

3. Basrawi, F., et al., J. Sol. Energ. Eng., 137(6): p. 061009 (2015).

4. Ibrahim, T.K. and M. Rahman, Adv. Sci. Lett., 13(1): p. 263-268 (2012).

5. Chen, W., et al., Appl. Therm. Eng., 111: p. 550-561 (2017).

6. Ifaei, P., J. Rashidi, and C. Yoo, Energ. Convers. Manage., 123: p. 610-624 (2016).

7. Varma, G.V.P. and T. Srinivas, Enrgy. Proced., 90: p. 99-106 (2016).

8. Dincer, I. and H. Al $\square$ Muslim, Int. J. Energ. Res., 25(8): p. $727-739$ (2001).

9. Ghosh, S. and S. De, Energy, 31(2): p. 345-363 (2006).

10. Ibrahim, T.K. and M.N. Mohammed, Int. J. Energ. Sci. Eng., 1(2): p. 10 (2015). 
11. Ibrahim, T.K. and M.M. Rahman, Therm. Sci, 17(2): p. 497-508 (2013).

12. Ibrahim, T.K., M. Rahman, and K. Sharma. Influence of Operation Conditions on Performance of Combined Cycle Gas Turbine. in International Conference on Mechanical and Electrical Technology, 3rd,(ICMET-China 2011), Volumes 1-3. (2011).

13. Guo, S., P. Liu, and Z. Li, Appl. Energ., 165: p. 1037-1051 (2016).

14. Fu, P., et al., Energ. Convers. Manage., 130: p. 219-229 (2016).

15. Sharma, M. and O. Singh, Appl. Therm. Eng., 93: p. 614-622 (2016).

16. Álvarez-Fernández, M., L. del Portillo-Valdés, and C. Alonso-Tristán, Appl. Therm. Eng., 93: p. 598-605 (2016).

17. Ahmadi, G., et al., Appl. Therm. Eng., 112: p. 111-123 (2017).

18. Vandani, A.M.K., M. Bidi, and F. Ahmadi, Energ. Convers. Manage., 106: p. 1-9 (2015).

19. Pirasaci, T. and D.Y. Goswami, Appl. Energ., 162: p. 644-652 (2016).

20. Wu, X., et al., ISA T., 56: p. 241-251 (2015).

21. Ifaei, P., A. Ataei, and C. Yoo, Energ. Convers. Manage., 123: p. 625-642 (2016).

22. Xu, G., et al., Appl. Therm. Eng., 107: p. 1145-1157 (2016).

23. Ahmadi, G.R. and D. Toghraie, Renew. Sust. Energ. Rev., 56: p. 454-463 (2016). 